ISSN: 2162-3104 Print/ ISSN: 2166-3750 Online

Volume 6, Issue 3 (2016), pp. 678-699

(C) Journal of International Students

http://jistudents.org/

\title{
International Students' Motivation and Learning Approach: A Comparison with Local Students
}

\author{
Kah Loong Chue \\ National Institute of Education, Singapore \\ Youyan Nie \\ National Institute of Education, Singapore
}

\begin{abstract}
Psychological factors contribute to motivation and learning for international students as much as teaching strategies. 254 international students and 144 local students enrolled in a private education institute were surveyed regarding their perception of psychological needs support, their motivation and learning approach. The results from this study indicated that international students had a higher level of self-determined motivation and used a deep and surface learning approach more extensively than local students. Perceived psychological needs support positively predicted intrinsic motivation, identified regulation and a deep learning approach for both groups. There were also differences in the effects of motivation on learning approach between the two groups. Further possibilities for exploration are discussed in this study.
\end{abstract}

Keywords: International students, self-determined motivation, learning approach, deep learning, surface learning

In the past few decades, the number of students studying abroad has increased significantly from 0.8 million in 1975 to an estimated figure of 4.5 million in 2012 (OECD, 2015). These international students are prone to face adjustment issues that are unfamiliar to local students, primarily in the area of language proficiency and culture adaptation (Andrade, 2006) and this may impact their motivation and learning in the classroom (Robertson, Line, Jones, \& Thomas, 2000; Tompson \& Tompson, 1996). As such, lecturers in classes comprised of both groups of students will need to take 
into account differences in prior educational and cultural experiences when designing strategies to improve motivation and learning. For example, to address their lack of language proficiency, Chinese students use silence as a means to avoid making mistakes (Liu, 2001). However, this strategy could easily be mistaken by lecturers for a lack of interest or engagement in the subject (Liu, 2001). Previous research that dealt with this topic has focused mainly on differences in learning styles (Ramburuth \& McCormick, 2001) and the implementation of appropriate teaching strategies (Robertson et al., 2000; Tompson \& Tompson, 1996; Wong, 2004) or policies, services and programs (Ren \& Hagedorn, 2012; Stoynoff, 1997; Wicks, 1996). Relatively few studies have been conducted on psychological factors that contribute to motivation and learning for international students. Indeed, Robertson et al., (2000) noted that many academic staff neglected the impact of emotional and psychological dilemmas faced by international students (Robertson et al., 2000).

What are some psychological factors that might affect motivation and student's approach to learning? Self-determinant theory postulates that supports for autonomy, competence and relatedness contribute to the overall psychological growth of an individual (Deci \& Ryan, 2002). It is reasonable to conjecture that the same psychological supports would impact the motivation and learning of international students. Moreover, if international students have to face challenges which are unfamiliar to the local students, these psychological supports might have a greater impact on them than on local students. Thus, the purpose of this study is to examine the relationships of these psychological needs support on motivation and learning approaches for international students. Furthermore, this study also examines how such relationships amongst international students differ from their local counterparts.

\section{LITERATURE REVIEW}

In exploring this particular area, the psychological constructs from selfdeterminant theory (SDT) will be applied. Self-determinant theory is a broad motivational framework that is centered on the beliefs that all humans have basic innate psychological needs of autonomy, relatedness and competency and that social environments play an important role in the actualization of these needs (Deci \& Ryan, 2002; Deci, Vallerand, Pelletier, \& Ryan, 1991). According to SDT, motivation can be categorized into distinct types along a self-determinant continuum. Amotivation lies on one extreme end of the continuum and represents a complete lack of motivation. People who are amotivated either do not act or act passively. At the other extreme end lies intrinsic motivation which represents the pinnacle of self-determined behaviors. Individuals who are intrinsically motivated perform activities for their inherent fulfilment rather than some external stimuli. In the middle 
band lies extrinsic motivation which can be further differentiated into three types according to their level of self-determination: External regulation, Introjection, Identification. External regulation is caused wholly by externally imposed rewards or punishment. Introjection occurs when individuals impose their own internal rewards or constraints (e.g. guilt, shame or obligation). Identification takes place when individuals can identify with the reason for behavior.

In recent years, findings regarding SDT in the field of education has shown that a higher level of self-determinant leads to positive educational outcomes, i.e. deeper engagement, better conceptual learning and higher persistence (Areepattamannil, Freeman, \& Klinger, 2011; Black \& Deci, 2000; Lin, McKeachie, \& Kim, 2001; Moneta \& Siu, 2002; Pelletier, Fortier, Vallerand, \& Briere, 2001; Standage, Duda, \& Ntoumanis, 2005; Vansteenkiste, Lens, \& Deci, 2006; Wang \& Guthrie, 2004; Zhou, Ma, \& Deci, 2009; Zhu \& Leung, 2011). To develop a higher sense of selfdetermination towards intrinsic motivation, an individual's basic psychological needs of autonomy, competence and relatedness must be satisfied (Deci et al., 1991). This requires the awareness of internal factors (e.g. an individual's age, gender, cognitive ability) and the introduction of external social factors (e.g. degree of autonomy support in the environment) (Wehmeyer et al., 2011). When social factors satisfy the three basic psychological needs, one can expect intrinsic motivation to be facilitated. In contrast, when these needs are thwarted, the individual's motivation is diminished (Ryan \& Deci, 2000b).

Autonomy refers to the experience of one's behavior as volitional. An environment that supports students' autonomy can be achieved by tapping on inner motivational resources, minimizing external pressure through language and providing explanatory rationale to transform any task into one of personal value (Reeve, 2009). Competence refers to the experience of one's interactions with the surroundings as effective. Students' competence can be supported by introducing appropriate learning activities and providing students with the appropriate tools and feedback for improvement (Niemiec \& Ryan, 2009). Relatedness refers to the experience of a sense of belonging and connectedness to a group. This is realized when students feel that a teacher genuinely respects and cares for them (Ryan \& Deci, 2000a). Recent research has combined the needs for autonomy, competence and relatedness into one composite variable and the satisfaction of these needs has been positively associated with self-determined motivation, i.e. intrinsic motivation, identified motivation and introjected motivation (Chen \& Jang, 2010; Jang, Reeve, Ryan, \& Kim, 2009; W. C. Liu, Wang, Tan, Koh, \& Ee, 2009; Standage, Duda, \& Ntoumanis, 2003; Standage et al., 2005) but negatively associated with external regulation and amotivation (W. C. Liu et al., 2009; Standage et al., 2003, 2005). 


\section{Approaches to learning}

The concept of learning approaches is derived from the seminal work of Marton and Saljo (1976). In essence, a student's approach to learning could be classified into two categories based on their study behavior. Students, who apply a deep learning strategy read widely, interrelate with previous relevant knowledge and try to connect their information with other subjects. Students who apply a surface learning strategy do the bare essentials, relying mainly on rote learning and memorization (Biggs, 1987). Naturally, most educators would wish to inculcate a deep learning approach in students. As such, numerous attempts have been made to identify the factors that induce deep learning. To categorize these factors and their impacts, Baeten (2010) conducted a study of previous literature and established that these factors can be grouped into three areas. Contextual factors refer to the actual learning environment, e.g. teaching methods, assessment, feedback and cognitive scaffolding. Perceived contextual factors refer to the manner in which students interpret instructional interventions, e.g. workload, teaching, supportiveness and relevance. Student factors refer to individual level factors, e.g. gender, personality, motivation. At the same time, it was acknowledged that a lot of these variables have yet to be empirically investigated (Baeten, Kyndt, Struyven, \& Dochy, 2010).

Previous studies focusing on the relationship between motivation and learning approaches have generally associated intrinsic motivation with deep learning and extrinsic motivation with surface learning (Entwistle, 1986). This is not surprising as many behaviors are typical of both intrinsic motivation and deep learning, e.g. performing tasks based on inherent satisfaction. However, the various types of extrinsic motivation as postulated by SDT were not considered in most studies pertaining to motivation and learning approach.

The distinction between the various types of extrinsic motivation is important. Firstly, identification is usually classified as autonomous motivation and has been associated with positive results whereas introjection and external regulation have been associated with negative results (e.g. Pelletier et al., 2001). Secondly, whilst external regulation consistently predicted negative outcomes, introjected regulation has shown correlations with both positive and negative outcomes ( $\mathrm{Ng}$ et al., 2012). Lastly, studies have indicated that students are generally motivated by extrinsic factors (Tan, Goh, Chia, \& Treagust, 2001; Yee, 2011). It is therefore essential that a distinction be made between partial external regulation and full external regulation so that the appropriate strategies can be employed to improve students' approaches to learning. 


\section{International students in Singapore}

To complement the public education institutions in Singapore, private educational institutes offer a range of education programs at the diploma, undergraduate and postgraduate levels to both local and international students. The private educational institutes have partnered with overseas universities (typically from UK, US or Australia) to provide external degree programs, thereby providing students the opportunity to acquire qualifications of foreign universities whilst studying in Singapore. In 2012, there was a total enrolment of 227,000 students in the private educational institutes, of which $44 \%$ were international students (Council of Private Education, 2012). Many of them hail from different countries in Asia, thus creating an immensely diverse and heterogeneous student profile. The push and pull factors for these international students are usually compliance with their parents' desires, inability to secure a place in their countries' prestigious universities, lower costs than western countries, lower safety concerns and the prospects of learning English in a bilingual society (Kitty, 2005).

Previous research studies on international students have largely concentrated on the East-West divide or more commonly the collectivisticindividualistic worldview. For example, results pertaining to approaches to learning have indicated that students in Eastern societies tend to emphasize rote memorization whilst their Western counterparts focus on conceptual understanding (Biggs, 1991; Murphy, 1987). However, in recent years, the notion that culture is represented by a set of values embracing individualism or collectivism has been replaced by a systems view of culture (Kitayama, 2002). This alternate view proposes that culture is a dynamic system made up of many loosely organized but connected elements such as practices and associated mental processes. Each individual's psychological processes and behaviors are organized around efforts to coordinate with a system of practices and public meanings. The systemic view of culture explicitly refutes the notion that Eastern and Western societies are composed of different core values. Instead, all psychological processes are potentially available to all groups of people (Kitayama, 2002). From this viewpoint, it is conceivable that the motivation and learning processes of international and local students within an educational institute may be vastly different from each other. For example, international students usually choose to study abroad for academic and personal growth, better career prospects and economic benefits (Eder, Smith, \& Pitts, 2010; Li \& Bray, 2007) and this may show a tendency to be extrinsically motivated. They could also have an intention to avoid disadvantageous conditions in their home country (Valery Chirkov, Vansteenkiste, Tao, \& Lynch, 2007). Before finalizing the decision to study abroad, they would also have to consider many factors such as the host countries' reputation for quality and cost issues (Mazzarol \& Soutar, 
2002), that local students would not have to contend with. These reasons suggest that international students demonstrate a significant amount of forward thinking and planning which may result in different learning processes from their local counterparts.

In addition, international students face social and academic adjustment challenges unfamiliar to local students. Social adjustment were ascribed to less social support and social connectedness whilst academic adjustment challenges were mainly attributed to English language proficiency (Andrade, 2006; Yeh \& Inose, 2003). They experience more anxiety and stress, thus requiring different levels and types of support to foster their cross-cultural learning skills (Andrade, 2006; Yamazaki \& Kayes, 2004). International and local students also differ in their learning systems (Ramsay, Barker, \& Jones, 1999; Zhao, Kuh, \& Carini, 2005). Furthermore, faculty staff often have a different perception of the behaviors of international students (Robertson et al., 2000; Tompson \& Tompson, 1996). For example, academic staff felt that international students lack writing and critical thinking skills whereas international students had difficulties understanding the instructor's use of colloquial language (Robertson et al., 2000).

Research in this area has emphasized the implementation of appropriate teaching strategies (Robertson et al., 2000; Tompson \& Tompson, 1996; Wong, 2004) or policies, services and programs (Ren \& Hagedorn, 2012; Stoynoff, 1997; Wicks, 1996) but have largely neglected the motivational and psychological needs of these students. These needs are especially important to international students as a higher level of selfdetermination could lead to more beneficial cultural adaptation outcomes (Chirkov, Safdar, De Guzman, \& Playford, 2008; Chirkov et al., 2007).

Therefore, the current study will seek to address this gap in the literature by investigating the following research questions: (1) What are the differences in motivation and learning approaches between local and international students? (2) How does perceived psychological needs support contribute to motivation and learning approach of international students? (3) How do the relationships between perceived psychological needs support, motivation and learning approach differ for local and international students? Based on the framework of SDT and previous research, the hypothesized model for both groups of students is represented in Figure 1. Specifically, perceived psychological needs support would be positively associated to self-determined motivation (intrinsic motivation, identified regulation, introjected regulation) and negatively associated to external regulation and amotivation. A deep learning approach would be positively predicted by intrinsic motivation, identified regulation and introjected regulation as these motivation types have elements of self-determination. A surface learning approach would be positively predicted by identified regulation, introjected 
regulation and external regulation. Amotivation would be negatively associated with both deep and surface learning as a lack of interest should naturally correspond to a lack of learning. Similarly, as perceived contextual factors play a role in determining learning approaches, perceived psychological needs support would positively predict deep learning and negatively predict surface learning.

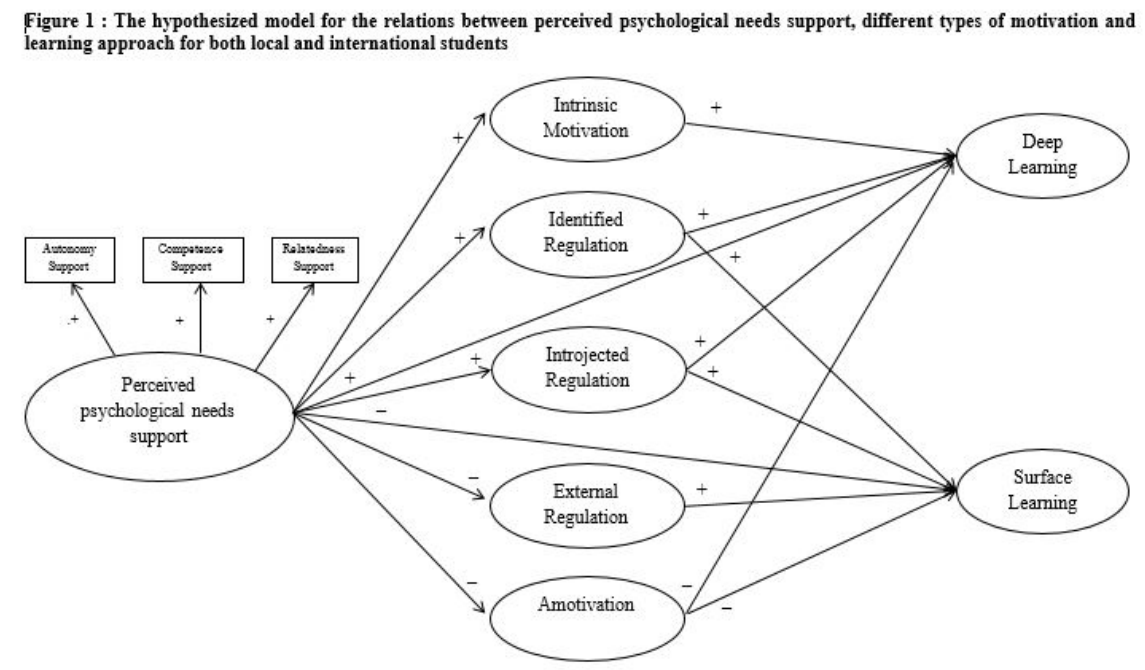

\section{RESEARCH METHOD}

\section{Sample}

The participants in this study were 401 students enrolled in a business mathematics course at a private educational institute in Singapore. The sample consisted of 144 local students $(84$ male, 59 female, mean age $=$ $20.4, \mathrm{SD}=2.64)$ and 254 international students (99 male, 155 female, mean age $=19.0, \mathrm{SD}=1.72)$. Three participants did not state their nationality and gender. English is the medium of instruction in the module. To ensure that students had sufficient time for perceptions of autonomy, competency and relatedness to be formed, the survey was conducted in the middle of the semester. The total time required to complete all the questionnaires is approximately 15 minutes. All students provided their background and demographic information.

\section{Measures}

Perceived psychological needs support. Perceived psychological needs support was measured with three subscales (i.e. perceived autonomy support, perceived competency support, perceived relatedness support) that 
were adapted from a modified version of a raters scale for perceived autonomy support (Reeve, Jang, Carrell, Jeon, \& Barch, 2004), the Intrinsic Motivation Inventory for perceived competence and the Need for Relatedness scale for perceived relatedness. Each subscale had five items. Example items from the subscales include "My lecturer explains the rationale for the value of tasks" (perceived autonomy), "My lecturer makes us feel like we are good at math" (perceived competence) and "My lecturer cares for our learning" (perceived relatedness). The three factors are further collapsed into a single composite factor. A second order confirmatory factor analysis with three factors at the first level and one factor at the second level showed an adequate fit for the data $\chi 2(84, N=401)=280.576, p<.01$, TLI $=.93, \mathrm{CFI}=.95$, RMSEA $=.076$. The subscales showed good internal consistency reliability ( $\alpha=0.89$ for perceived autonomy support, $\alpha=0.86$ for perceived competency support, $\alpha=0.88$ for perceived relatedness support).

Motivation. Motivation was assessed using an adapted version of the Perceived Locus of Causality (PLOC) questionnaire (Goudas, Biddle, \& Fox, 1994) and the Academic Motivation Scale (Vallerand et al., 1992) . There were five subscales to measure intrinsic motivation, identified regulation, introjected regulation, external regulation and amotivation. Each subscale had four items. All items were altered to fit a mathematics module context (e.g. Intrinsic motivation - I take part in mathematics lessons because I enjoy learning new skills/techniques in math). A five-factor confirmatory factor analysis provided an adequate fit for the data $\chi 2(140, N$ $=401)=484.422, p<.01$, TLI $=.91$, CFI $=.93$, RMSEA $=.078$. The subscales showed good internal consistency reliability $(\alpha=0.96$ for intrinsic motivation, $\alpha=0.89$ for identified regulation, $\alpha=0.70$ for introjected regulation, $\alpha=0.78$ for external regulation, $\alpha=0.87$ for amotivation).

Learning Approach. Surface and deep learning were measured using a modification of the revised two-factor version of the Learning Process Questionnaire (Kember, Biggs, \& Leung, 2004) and the Motivated Strategies for Learning Questionnaire (Elliot, McGregor, \& Gable, 1999; Pintrich, Smith, García, \& McKeachie, 1993). Two subscales assessing deep and surface strategy were modified from the questionnaire to suit a mathematics module context. Each subscale had six items and scores for each item were extended to a 7-point scale. A two- factor confirmatory factor analysis provided an adequate fit for the data $\chi 2(23, N=401)=$ $74.475, p<.01$, TLI $=.91$, CFI $=.96$, RMSEA $=.075$. The subscales showed good internal consistency reliability ( $\alpha=0.82$ for deep learning, $\alpha=$ 0.72 for surface learning). 
Demographical variables. The demographical variables of age, gender $($ male $=0$, female $=1$ ) and nationality $($ Local students $=0$, International students $=1$ ) were measured.

\section{RESULTS}

Descriptive statistics and correlation coefficients among the variables for the two groups were computed and inspected. Gender was not significantly correlated to deep or surface learning for both groups indicating that any relationships between the variables were invariant across gender. Path analysis was conducted to examine the significant direct and indirect relations between perceived psychological needs support, motivation and learning approaches for both groups. Multi group analysis was conducted to determine if there were significant differences in path coefficients between the two groups.

\section{Descriptive statistics and zero-order correlations}

Descriptive statistics and correlations for international and local students are presented in Table 1 and 2 respectively. International students reported a significantly higher level of perceived psychological needs support $(t(396)=-4.63, p<.001, d=.47)$, intrinsic motivation $(t(396)=$ $5.57, p<.001, d=.56)$, identified regulation $(t(396)=-5.24, p<.001, d=$ $.53)$, external regulation $(t(396)=-3.14, p<.01, d=.32$, deep learning $(t(396)=-2.92, p<.01, d=.29)$ and surface learning $(t(396)=-2.03, p<$ $.05, d=.20)$ but a lower level of amotivation $(t(396)=2.87, p<.01, d=.29)$ than local students.

Table l.: Means, standard deviations and correlations among variables for international students

\begin{tabular}{|c|c|c|c|c|c|c|c|c|c|c|c|}
\hline Variables & Mean & SD & 1 & 2 & 3 & 4 & 5 & 6 & 7 & 8 & 9 \\
\hline 1 Needs support & 5.20 & .93 & 1.00 & & & & & & & & \\
\hline 2 Intrinsic Motivation & 4.70 & 1.63 & $.38 * * *$ & 1.00 & & & & & & & \\
\hline 3 Identified Regulation & 5.18 & 1.31 & $.43 * * *$ & $.47 * * *$ & 1.00 & & & & & & \\
\hline 4 Introjected Regulation & 4.13 & 1.32 & .08 & .04 & $.13^{* *}$ & 1.00 & & & & & \\
\hline 5 External Regulation & 4.21 & 1.30 & .04 & -19 **** & .08 & $.51 * * *$ & 1.00 & & & & \\
\hline 6 Amotivation & 2.92 & 1.44 & $-.15^{* *}$ & $-37 * * *$ & $-.40^{* * * *}$ & .07 & $.32 * * *$ & 1.00 & & & \\
\hline 7 Deep Learning & 5.33 & 1.01 & $.43 * * *$ & $.41^{* * *}$ & $.49 * * *$ & $.16 * * *$ & .02 & $-.38 * * *$ & 1.00 & & \\
\hline 8 Surface Learning & 4.16 & 1.13 & $.12^{*}$ & .05 & $.27 * * *$ & $.19^{* * * *}$ & $.22 * * *$ & .06 & $.17^{* * * *}$ & 1.00 & \\
\hline 9 Gender & & & .01 & -.08 & .07 & $.12^{*}$ & .10 & -.03 & .10 & .08 & 1.00 \\
\hline
\end{tabular}

For both groups of students, there were surprisingly no significant correlations between perceived psychological needs support and introjected regulation and external regulation. Several differences in bivariate correlations between the two groups were quite evident. For example, surface learning was positively associated with only external regulation for 
local students whereas it was positively associated with perceived psychological needs support, identified regulation, introjected regulation and external regulation for international students.

Table 2 : Means, standard deviations and correlations among variables for local students

\begin{tabular}{llccccccccccc}
\hline \multicolumn{1}{c}{ Variables } & Mean & SD & 1 & 2 & 3 & 4 & 5 & 6 & 7 & 8 & 9 \\
\hline 1 & Needs support & 4.74 & 1.01 & 1.00 & & & & & & & & \\
2 & Intrinsic Motivation & 3.73 & 1.74 & $.20^{* *}$ & 1.00 & & & & & & \\
3 & Identified Regulation & 4.43 & 1.47 & $.30^{* * *}$ & $.47^{* * *}$ & 1.00 & & & & & & \\
4 & Introjected Regulation & 4.07 & 1.39 & .06 & $.18^{* *}$ & $.33^{* * *}$ & 1.00 & & & & & \\
5 & External Regulation & 3.75 & 1.56 & .04 & -.08 & .11 & $.46^{* * *}$ & 1.00 & & & & \\
6 & Amotivation & 3.39 & 1.73 & $-.32^{* * *}$ & $-.50^{* * *}$ & $-.60^{* * *}$ & $-.15^{*}$ & .10 & 1.00 & & & \\
7 & Deep Learning & 5.02 & 1.09 & $.41^{* * *}$ & $.25 * * *$ & $.43^{* * *}$ & $.25 * * *$ & .08 & $-.31^{* * *}$ & 1.00 & & \\
8 & Surface Learning & 3.92 & 1.17 & .10 & .05 & .08 & .03 & $.14^{*}$ & .03 & -.01 & 1.00 & \\
9 & Gender & & &. .11 & -.02 & .02 & -.04 & -.01 & .01 & .00 & -.04 & 1.00 \\
\hline${ }^{*} p<.10 ;{ }^{* *} p<.05 ; * * * 01$ \\
\end{tabular}

\section{Path analysis}

The model for both groups was examined via SEM using the asymptotically distribution-free estimation method to cater for multivariate non-normality. In both path models, the residuals of the various motivational types were allowed to be correlated to represent their interrelationship as recommended by Standage et al. (2003). Non-significant paths were removed from the model. Differences in pairwise path coefficients were inspected using multi-group analysis in AMOS.

The final path models for international students and local students are presented in Figure 2 and 3 respectively. An examination of the fit indices suggested a good fit for the data, $\chi 2(34)=44.23, p=.113$, TLI $=$ $.95, \mathrm{CFI}=.98$, RMSEA $=.028$. In both path models, perceived psychological needs support positively predicted intrinsic motivation and identified regulation, negatively predicted amotivation and had no associations with introjected regulation and external regulation. In the path model for international students, a deep learning approach was positively predicted by perceived psychological needs support, intrinsic motivation, identified regulation and introjected regulation but negatively predicted by amotivation whereas a surface learning approach was positively predicted by identified regulation and amotivation. However, in the path model for local students, perceived psychological needs support and identified regulation predicted a deep learning approach. No motivation types predicted a surface learning approach (See Table 3).

A comparison of pairwise path coefficients across the two groups also revealed significant differences in the path coefficients between perceived psychological needs support and intrinsic motivation $(p=.013)$ and perceived psychological needs support and amotivation $(p=.062)$ (See Table 4). International students reported a greater impact of perceived 
psychological needs support on intrinsic motivation $(\beta=.42$ compared to $\beta$ $=.16)$ and a lesser impact of perceived psychological needs support on amotivation $(\beta=-.17$ compared to $\beta=-.37)$.

Figure 2: The path analysis for the relations between perceived psychological needs support, different types of motivation and learning approach for international students

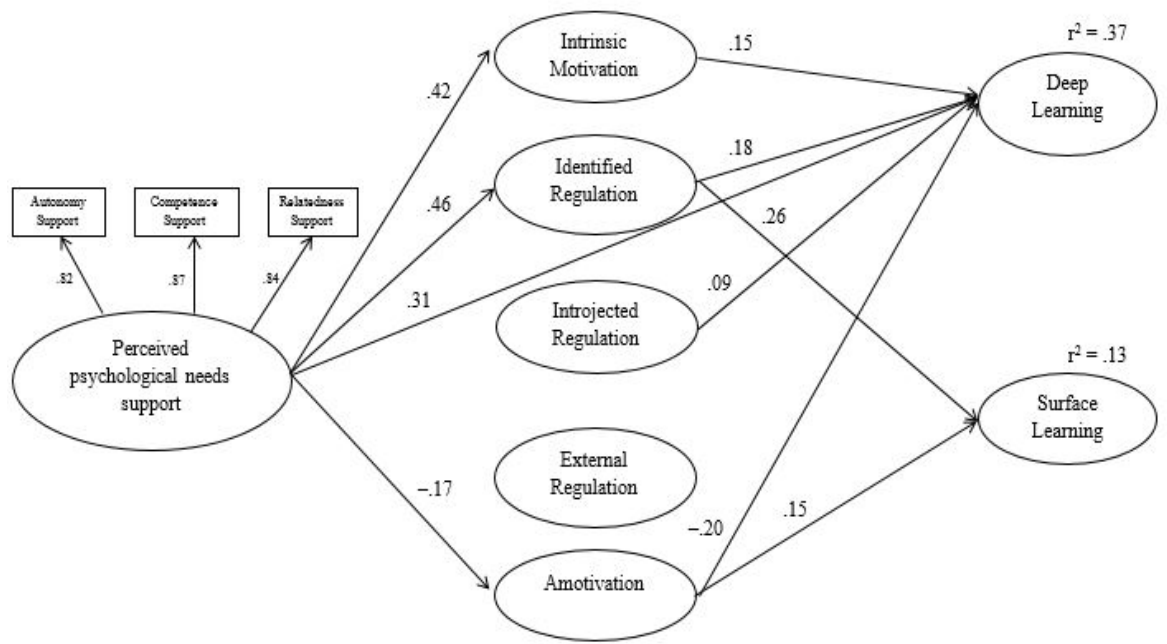

Only significant paths $(p<10)$ are represented. The numbers next to the solid lines are standardized parameter estimates.

Figure 3: The path analysis for the relations between perceived psychological needs support, different types of motivation and learning approach for local students

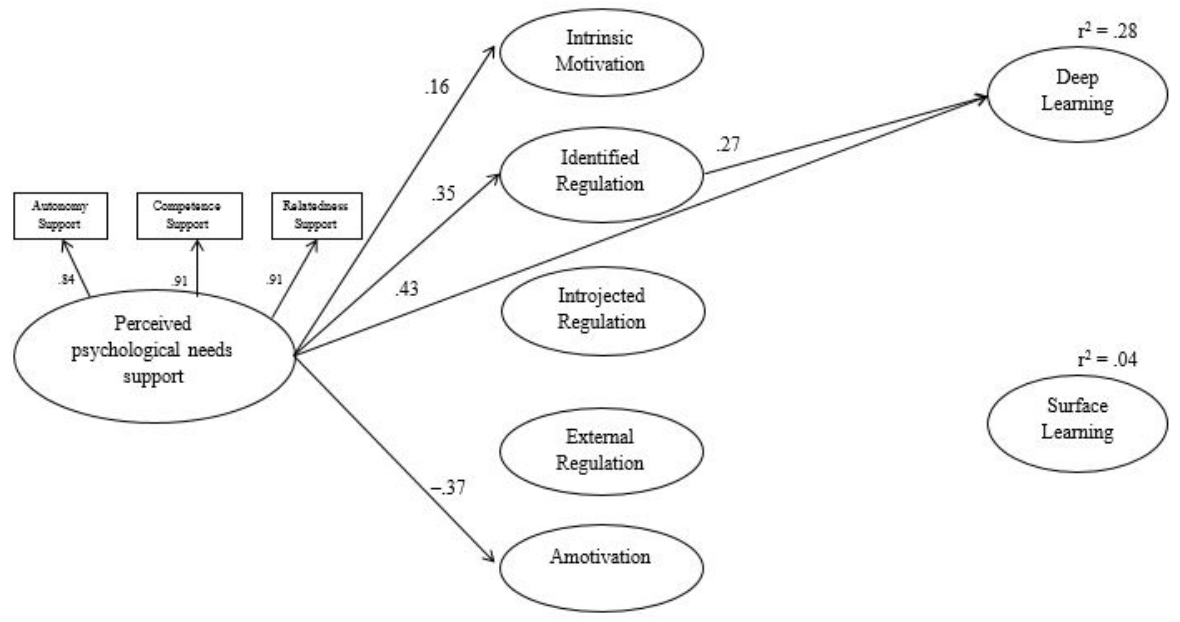

Only significant paths $(p<.10)$ are represented. The numbers next to the solid lines are standardized parameter estimates. 
Table 3: Significant standardized parameter estimates of direct and indirect effects for international and local students

\begin{tabular}{|c|c|c|c|c|}
\hline \multirow[t]{2}{*}{ Parameters } & \multicolumn{2}{|c|}{ International } & \multicolumn{2}{|c|}{ Local } \\
\hline & $\beta$ & $p$-value & $\beta$ & $p$-value \\
\hline Perceived psychological needs support $\rightarrow$ Intrinsic Motivation & .421 & $<.001$ & .157 & .067 \\
\hline Perceived psychological needs support $\rightarrow$ Identified Regulation & .463 & $<.001$ & .349 & $<.001$ \\
\hline Perceived psychological needs support $\rightarrow$ Introjected Regulation & \multicolumn{2}{|c|}{ n.s. } & \multicolumn{2}{|c|}{ n.s. } \\
\hline Perceived psychological needs support $\rightarrow$ External Regulation & \multicolumn{2}{|c|}{ n.s. } & \multicolumn{2}{|c|}{ n.s. } \\
\hline Perceived psychological needs support $\rightarrow$ Amotivation & -.165 & .012 & -.372 & $<.001$ \\
\hline Perceived psychological needs support $\rightarrow$ Deep Learning & .312 & $<.001$ & .427 & $<.001$ \\
\hline Perceived psychological needs support $\rightarrow$ Surface Learning & \multicolumn{2}{|c|}{ n.s. } & \multicolumn{2}{|c|}{ n.s. } \\
\hline Intrinsic Motivation $\rightarrow$ Deep Learning & .150 & .012 & \multicolumn{2}{|c|}{ n.s. } \\
\hline Identified Regulation $\rightarrow$ Deep Learning & .176 & .005 & .274 & .007 \\
\hline Introjected Regulation $\rightarrow$ Deep Learning & .094 & .075 & \multicolumn{2}{|c|}{ n.s. } \\
\hline Amotivation $\rightarrow$ Deep Learning & -.200 & $<.001$ & \multicolumn{2}{|c|}{ n.s. } \\
\hline Identified Regulation $\rightarrow$ Surface Learning & .261 & $<.001$ & \multicolumn{2}{|c|}{ n.s. } \\
\hline Introjected Regulation $\rightarrow$ Surface Learning & \multicolumn{2}{|c|}{ n.s. } & \multicolumn{2}{|c|}{ n.s. } \\
\hline External Regulation $\rightarrow$ Surface Learning & \multicolumn{2}{|c|}{ n.s. } & \multicolumn{2}{|c|}{ n.s. } \\
\hline Amotivation $\rightarrow$ Surface Learning & .150 & .049 & \multirow{2}{*}{\multicolumn{2}{|c|}{ n.s. }} \\
\hline Perceived psychological needs support $\rightarrow$ Intrinsic Motivation $\rightarrow$ Deep Learning & .063 & .010 & & \\
\hline Perceived psychological needs support $\rightarrow$ Identified Regulation $\rightarrow$ Deep Learning & .081 & .004 & .096 & .003 \\
\hline Perceived psychological needs support $\rightarrow$ Amotivation $\rightarrow$ Deep Learning & .033 & .009 & \multicolumn{2}{|c|}{ n.s. } \\
\hline Perceived psychological needs support $\rightarrow$ Identified Regulation $\rightarrow$ Surface Learning & .121 & .001 & \multicolumn{2}{|c|}{ n.s. } \\
\hline Perceived psychological needs support $\rightarrow$ Amotivation $\rightarrow$ Surface Learning & -.025 & .042 & \multicolumn{2}{|c|}{ n.s. } \\
\hline
\end{tabular}

Table 4: Critical ratios for significant differences between path coefficients of local and international students

\begin{tabular}{lcc}
\hline Parameters & z-value & $p$-value \\
\hline Perceived psychological needs support $\rightarrow$ Intrinsic Motivation & 2.472 & .013 \\
Perceived psychological needs support $\rightarrow$ Amotivation & 1.868 & .062 \\
\hline
\end{tabular}

\section{DISCUSSION AND CONCLUSIONS}

The current study was designed to examine and compare the relations between perceived psychological needs support, five types of motivation as specified by SDT and approaches to learning for both international and local students. The results indicate that international students have a higher level of intrinsic motivation, identified regulation, external regulation, deep learning and surface learning but a lower level of amotivation. An inspection of the path models indicate the following key observations congruent to both groups : 1) perceived psychological needs support positively predicted intrinsic motivation, identified regulation, negatively predicted amotivation but has no effect on introjected and external regulation, 2) a deep learning approach was predicted by perceived psychological needs support and identified regulation. An examination of the differences between international and local students indicated that 1) a deep learning approach was positively predicted by intrinsic motivation, identified regulation and introjected regulation but negatively predicted by amotivation for international students whereas there were no effects for local students, 2) a surface learning approach was positively predicted by 
identified regulation and amotivation for international students whereas there were no effects for local students.

\section{Motivation and learning patterns between international and local students}

International students reported a higher level of intrinsic motivation, identified regulation and external regulation but a lower level of amotivation than local students. This may be due to the reason that international students usually have a specific aim in mind when they opt to study overseas. For example, when they choose to do so for personal or professional growth (Eder et al., 2010; Li \& Bray, 2007), this will naturally correspond to a higher intrinsic motivation than local students who may be just following a natural academic progression. By the same token, when international students opt to study overseas for better career prospects and an enhanced social status (Li \& Bray, 2007), this will correspond to a higher identified regulation and lower amotivation. Finally, it may be that international students who do not pass the course will have their students' visa revoked. The continuous threat of an external penalty will correspond to a higher external regulation.

International students also reported a significantly higher use of both deep and surface learning, indicating that they have a stronger focus on concepts and connections as well as memorisation than local students. Baeten (2010) had suggested that a myriad of student factors influence the adoption of learning approach, such as level of cognitive development, prior educational experience and self-direction in learning (Baeten et al., 2010). International students may have to resolve many issues that are unfamiliar to local students, before finalizing a decision to study abroad. This issues range from a consideration of push factors e.g. the availability of educational opportunities in their home country to pull factors, e.g. the quality of education in the host country and financial costs of staying overseas (Mazzarol \& Soutar, 2002). This suggests that international students may have a higher level of cognitive development and self-direction than local students. However, further investigations will need to be carried out before any definite conclusions can be made.

\section{The beneficial role of perceived psychological needs support}

The beneficial role of perceived psychological needs support is consistent for both local and international students. The present results support the generalizability of SDT claims that perceived psychological needs support positively predicted self-determined motivation (intrinsic and identified motivation) and negatively predicted amotivation in both local and international students, thus highlighting the importance of the socioenvironmental context in education. Surprisingly, differing from previous 
findings, the perceived psychological need supports were not associated with introjected and external regulation. One possible reason could lie with the antecedents of these motivational types. For example, supporting psychological needs may not have any effect on the lack of external financial resources. Future research could attempt to explore in greater detail the antecedents of the various motivational constructs and their consequences.

A pairwise comparison indicated that an increase of perceived psychological needs support had a greater impact on intrinsic motivation and amotivation for international students. Specifically, the same level of perceived psychological needs support would result in a higher level of intrinsic motivation and a lower level of amotivation for international students. A possible reason may be that the most critical adjustment factors for international students in the host country are proficiency in the English language and building a social network (Andrade, 2006). According to SDT, perceived psychological needs support comprises of supports for autonomy, competence and relatedness. Supports for competence might have addressed the issue of English language proficiency whilst supports for relatedness might have addressed the issue of building a social network indirectly. As local students do not face similar adjustment issues, this may account for the disparity in the relationship.

With regard to the relationship between perceived psychological needs support and learning approaches, the results indicated that perceived psychological needs support is a significant positive predictor of deep learning but not a significant predictor of surface learning for both groups of students. Previous studies had confirmed the importance of the learning environment in cultivating deep learning (Entwistle, 2000; Hall, Ramsay, \& Raven, 2004) and strategies have been advocated to create a suitable environment, e.g. providing relevant feedback and clear objectives, creating opportunities for questions, making efforts to understand students' difficulties and offering options for students do decide what and how they learn (Trigwell \& Prosser, 1991). These strategies are synonymous with strategies for providing supports for autonomy, competence and relatedness, thus reinforcing the premise that perceived supports for psychological needs predicts deep learning.

\section{Differences between international and local students}

Several differences emerged upon comparing the findings of international and local students. Firstly, aligned with previous research, a deep learning approach was positively predicted by intrinsic motivation, identified regulation and introjected regulation for international students. All three motivational types encompass, to different extents, an internal perceived locus of causality which may be a significant precursor to a deep 
learning approach. However, the same three motivational types had no significant effect on deep learning for local students. One possible reason might lie in the behaviors linked with the motivational constructs. For example, performing tasks based on inherent satisfaction is a common characteristic to intrinsic motivation. But what does it mean for local students to be interested in math for inherent satisfaction? In Singapore, the central focus for primary and secondary mathematics education is problem solving (Ministry of Education, 2007a, 2007b). Teaching activities are assessment focused (Hogan et al., 2013) and mainly involve practicing procedural routines (Fan \& Zhu, 2007). Students enjoy math when they can easily get high marks after much practice of routine close-ended questions (Fan et al., 2005). Hence, it is possible that local students may be intrinsically motivated to do math problems, i.e. towards procedural understanding, but do not strive for conceptual understanding nor establishing links with other subjects.

Secondly, amotivation negatively predicted deep learning for international students but had no significant effect for local students. Although the bivariate correlation between amotivation and deep learning was significantly negative for local students, this relationship did not exist in the multivariate path analysis, suggesting that some other variable may affect the relation between amotivation and deep learning. For example, previous research had proposed that the antecedents of amotivation comprised of four factors: ability beliefs, effort beliefs, task characteristics and task value (Legault, Green-Demers, \& Pelletier, 2006). Of the four factors, ability beliefs and effort beliefs were related to academic outcomes whilst task characteristics, task value and effort beliefs are tied to problem behaviors. It is plausible that international students are amotivated because of ability beliefs and effort beliefs whereas local students are amotivated because of task characteristics and task value. If international students believe that they are neither intelligent nor able to expend the necessary effort to do well, this might have a negative influence on their types of cognitive strategies used (Wigfield \& Eccles, 1994). Conversely, local students might not believe in the value of the subject in which they are studying but this belief do not interfere with the manner in which they approach learning.

Lastly, a surface learning approach was positively predicted by identified regulation whereas there was no effect for local students. This indicates that for international students, a greater level of identification with the importance of the subject will result in a higher level of surface learning, suggesting that international students recognize the need for both deep and surface approaches to learning in order to achieve good academic outcomes. Likewise, amotivation positively predicted surface learning for international students but had no effect on local students. As mentioned in the preceding 
paragraph, international students may be amotivated because of ability beliefs and effort beliefs.

\section{IMPLICATIONS}

One primary aim for educators is to inculcate self-determined motivation in students. The findings in this study suggest that the most effective strategy for international students is to increase support of their psychological needs. Although previous research has indicated that all students will benefit when these needs are supported (Standage et al., 2005), it would appear that there is a greater impact on international students than local students. Specifically, educators could aim to support feelings of relatedness by establishing a sense of connectedness with the students (Niemiec \& Ryan, 2009). For example, separate dialogue sessions could be conducted with international students. This serves to acknowledge the students' backgrounds and expresses an interest in them. Instructions during lessons could also emphasize a caring aspect by recognizing that each student has his or her own interests and emotions (Sheldon \& Filak, 2008).

An autonomy supportive climate could possibly be created by nurturing students' inner resources, displaying patience and acknowledging student's expression of negative affect (Reeve, 2009). For example, educators can openly ask what international students need or want and consequently modify the lesson accordingly. Students could also be offered the option to evaluate themselves from a self-referent standard (Stefanou, Perencevich, DiCintio, \& Turner, 2004). Furthermore, as international students may not be proficient in English, displaying patience and acknowledging their difficulties may also increase their self-determination level. In addition, supporting international students' needs of competence addresses issues pertaining to their language proficiency and prior academic knowledge. This could be achieved by introducing optimally challenging learning tasks with appropriate tools and feedback (Niemiec \& Ryan, 2009).

\section{LIMITATIONS}

A number of limitations need to be considered in the present study. First, the current study is cross-sectional in design; hence, any causal conclusions cannot be drawn. For instance, because of an increase in the exposure of metacognitive skills, it is possible that students who adopt a deep learning approach will gradually enjoy performing tasks for intrinsic motives. Future studies might consider using an experimental or longitudinal design to help clarify the relationships. Second, the relative importance of autonomy support, competence support and relatedness support in the model could be explored in greater detail. For example, researchers have debated whether 
students in different cultures value autonomy equally (Markus \& Kitayama, 1991). International students who are separated from their home societies could have different perspectives of autonomy.

Third, some other variables such as prior knowledge were not considered as control variables. For example, one potential factor that could have a high impact is that of cultural distance which is described as the degree of incongruence between cultures (Popp, Love, Kim, \& Hums, 2010). Due to cultural similarities, students from Malaysia would experience a smaller cultural distance than a student from Korea. Although it would have been ideal in the present study to investigate if the country of origin makes a difference, the small sample size did not permit such an investigation.

\section{REFERENCES}

Andrade, M. S. (2006). International students in English-speaking universities adjustment factors. Journal of Research in International Education, 5(2), 131-154. doi: 10.1177/1475240906065589

Areepattamannil, S., Freeman, J. G., \& Klinger, D. A. (2011). Intrinsic motivation, extrinsic motivation, and academic achievement among Indian adolescents in Canada and India. Social Psychology of Education, 14(3), 427-439. doi: 10.1007/s11218-011-9155-1

Baeten, M., Kyndt, E., Struyven, K., \& Dochy, F. (2010). Using student-centred learning environments to stimulate deep approaches to learning: Factors encouraging or discouraging their effectiveness. Educational Research Review, 5(3), 243-260. doi: 10.1016/j.edurev.2010.06.001

Biggs, J. (1987). Student Approaches to Learning and Studying. Research Monograph. Australia: Australian Council for Educational Research Ltd.

Biggs, J. (1991). Approaches to learning in secondary and tertiary students in Hong Kong: Some comparative studies. Educational Research Journal, 6(1), 2739.

Black, A. E., \& Deci, E. L. (2000). The effects of instructors' autonomy support and students' autonomous motivation on learning organic chemistry: A selfdetermination theory perspective. Science Education, 84(6), 740-756. doi: 10.1002/1098-237X(200011)84:6<740::AID-SCE4>3.0.CO;2-3

Chen, K.-C., \& Jang, S.-J. (2010). Motivation in online learning: Testing a model of self-determination theory. Computers in Human Behavior, 26(4), 741-752. doi: 10.1016/j.chb.2010.01.011

Chirkov, V., Safdar, S., De Guzman, J., \& Playford, K. (2008). Further examining the role motivation to study abroad plays in the adaptation of international students in Canada. International Journal of Intercultural Relations, 32(5), 427-440.

Chirkov, V., Vansteenkiste, M., Tao, R., \& Lynch, M. (2007). The role of selfdetermined motivation and goals for study abroad in the adaptation of international students. International Journal of Intercultural Relations, 31(2), 199-222. doi: 10.1016/j.ijintrel.2006.03.002 
CPE. (2012). Annual Report 2011/2012. Singapore: Council of Private Education.

Deci, E. L., \& Ryan, R. M. (2002). Handbook of self-determination research: University Rochester Press.

Deci, E. L., Vallerand, R. J., Pelletier, L. G., \& Ryan, R. M. (1991). Motivation and education: The self-determination perspective. Educational Psychologist, 26(3-4), 325-346. doi: 10.1080/00461520.1991.9653137

Eder, J., Smith, W. W., \& Pitts, R. E. (2010). Exploring factors influencing student study abroad destination choice. Journal of Teaching in Travel \& Tourism, 10(3), 232-250. doi: 10.1080/15313220.2010.503534

Elliot, A. J., McGregor, H. A., \& Gable, S. (1999). Achievement goals, study strategies, and exam performance: A mediational analysis. Journal of Educational Psychology, 91(3), 549-563. doi: 10.1037/0022-0663.91.3.549

Entwistle, N. (1986). Approaches to Learning in Higher Education: Effects of Motivation and Perceptions of the Learning Environment. Paper presented at the Annual Meeting of the American Educational Research Association, San Francisco, CA.

Entwistle, N. (2000). Promoting deep learning through teaching and assessment: conceptual frameworks and educational contexts. Paper presented at the TLRP conference, Leicester.

Fan, L., Quek, K. S., Zhu, Y., Yeo, S. M., Pereira-Mendoza, L., \& Lee, P. Y. (2005). Assessing Singapore students' attitudes toward mathematics and mathematics learning: Findings from a survey of lower secondary students. Paper presented at the ICMI Regional Conference: The 3rd East Asia Regional Conference on Mathematics Education, hanghai, Nanjing, and Hangzhou, China, 2005.

Fan, L., \& Zhu, Y. (2007). From convergence to divergence: the development of mathematical problem solving in research, curriculum, and classroom practice in Singapore. ZDM, 39(5-6), 491-501. doi: 10.1007/s11858-0070044-1

Goudas, M., Biddle, S., \& Fox, K. (1994). Perceived locus of causality, goal orientations, and perceived competence in school physical education classes. British Journal of Educational Psychology, 64(3), 453-463. doi: 10.1111/j.2044-8279.1994.tb01116.x

Hall, M., Ramsay, A., \& Raven, J. (2004). Changing the learning environment to promote deep learning approaches in first-year accounting students. Accounting Education, 13(4), 489-505. doi: 10.1080/0963928042000306837

Hogan, D., Chan, M., Rahim, R., Kwek, D., Maung Aye, K., Loo, S. C., . . Luo, W. (2013). Assessment and the logic of instructional practice in Secondary 3 English and mathematics classrooms in Singapore. Review of Education, 1(1), 57-106. doi: 10.1002/rev3.3002

Jang, H., Reeve, J., Ryan, R. M., \& Kim, A. (2009). Can self-determination theory explain what underlies the productive, satisfying learning experiences of collectivistically oriented Korean students? Journal of Educational Psychology, 101(3), 644-661. doi: 10.1037/a0014241

Kember, D., Biggs, J., \& Leung, D. Y. (2004). Examining the multidimensionality of approaches to learning through the development of a revised version of 
the Learning Process Questionnaire. British Journal of Educational Psychology, 74(2), 261-279. doi: 10.1348/000709904773839879

Kitayama, S. (2002). Culture and basic psychological processes--toward a system view of culture: comment on Oyserman et al.(2002).

Kitty, L. (2005). Perceptions affecting PRC students' motivation in a private institute in Singapore. (Master of Arts (Educational Management)), National Institute of Education, Nanyang Technological University, Singapore.

Legault, L., Green-Demers, I., \& Pelletier, L. (2006). Why do high school students lack motivation in the classroom? Toward an understanding of academic amotivation and the role of social support. Journal of Educational Psychology, 98(3), 567-582. doi: 10.1037/0022-0663.98.3.567

Li, M., \& Bray, M. (2007). Cross-border flows of students for higher education: Push-pull factors and motivations of mainland Chinese students in Hong Kong and Macau. Higher Education, 53(6), 791-818. doi: 10.1007/s10734005-5423-3

Lin, Y.-G., McKeachie, W. J., \& Kim, Y. C. (2001). College student intrinsic and/or extrinsic motivation and learning. Learning and Individual Differences, 13(3), 251-258. doi: 10.1016/S1041-6080(02)00092-4

Liu, J. (2001). Construction Chinese faces in American classrooms. Asian Journal of English Language Teaching, 11, 1-18.

Liu, W. C., Wang, C., Tan, O. S., Koh, C., \& Ee, J. (2009). A self-determination approach to understanding students' motivation in project work. Learning and Individual Differences, 19(1), 139-145. doi: 10.1016/j.lindif.2008.07.002

Markus, H. R., \& Kitayama, S. (1991). Culture and the self: Implications for cognition, emotion, and motivation. Psychological Review, 98(2), 224. doi: 10.1037/0033-295X.98.2.224

Mazzarol, T., \& Soutar, G. N. (2002). "Push-pull" factors influencing international student destination choice. International Journal of Educational Management, 16(2), 82-90.

MOE. (2007a). Primary mathematics syllabus. Singapore: Curriculum Planning and Development Division.

MOE. (2007b). Secondary mathematics syllabus. Singapore: Curriculum Planning and Development Division.

Moneta, G. B., \& Siu, C. M. (2002). Trait Intrinsic and Extrinsic Motivations, Academic Performance, and Creativity in Hong Kong College Students. Journal of College Student Development, 43(5), 664-683.

Murphy, D. (1987). Offshore Education: A Hong Kong Perspective. Australian Universities' Review, 30(2), 43-44.

Ng, J. Y., Ntoumanis, N., Thøgersen-Ntoumani, C., Deci, E. L., Ryan, R. M., Duda, J. L., \& Williams, G. C. (2012). Self-determination theory applied to health contexts a meta-analysis. Perspectives on Psychological Science, 7(4), 325340. doi: 10.1177/1745691612447309

Niemiec, C. P., \& Ryan, R. M. (2009). Autonomy, competence, and relatedness in the classroom Applying self-determination theory to educational practice. Theory and Research in Education, 7(2), 133-144. doi: $10.1177 / 1477878509104318$ 
OECD. (2015). Education at a Glance 2015: OECD Publishing.

Pelletier, L. G., Fortier, M. S., Vallerand, R. J., \& Briere, N. M. (2001). Associations among perceived autonomy support, forms of self-regulation, and persistence: A prospective study. Motivation and Emotion, 25(4), 279306. doi: $10.1023 / \mathrm{A}: 1014805132406$

Pintrich, P. R., Smith, D. A., García, T., \& McKeachie, W. J. (1993). Reliability and predictive validity of the Motivated Strategies for Learning Questionnaire (MSLQ). Educational and Psychological Measurement, 53(3), 801-813. doi: $10.1177 / 0013164493053003024$

Popp, N., Love, A. W., Kim, S., \& Hums, M. A. (2010). Cross-cultural adjustments and international collegiate athletes. Journal of Intercollegiate Sport, 3(1), 163-181.

Ramburuth, P., \& McCormick, J. (2001). Learning diversity in higher education: A comparative study of Asian international and Australian students. Higher Education, 42(3), 333-350. doi: 10.1023/A:1017982716482

Ramsay, S., Barker, M., \& Jones, E. (1999). Academic Adjustment and Learning Processes: a comparison of international and local students in first-year university. Higher Education Research \& Development, 18(1), 129-144. doi: 10.1080/0729436990180110

Reeve, J. (2009). Why Teachers Adopt a Controlling Motivating Style Toward Students and How They Can Become More Autonomy Supportive. Educational Psychologist, 44(3), 159-175. doi: 10.1080/00461520903028990

Reeve, J., Jang, H., Carrell, D., Jeon, S., \& Barch, J. (2004). Enhancing students' engagement by increasing teachers' autonomy support. Motivation and Emotion, 28(2), 147-169. doi: 10.1023/B:MOEM.0000032312.95499.6f

Ren, J., \& Hagedorn, L. S. (2012). International Graduate Students' Academic Performance: What Are the Influencing Factors? Journal of International Students, 2(21), 135.

Robertson, M., Line, M., Jones, S., \& Thomas, S. (2000). International students, learning environments and perceptions: A case study using the Delphi technique. Higher education research and development, 19(1), 89-102. doi: $10.1080 / 07294360050020499$

Ryan, R. M., \& Deci, E. L. (2000a). Intrinsic and extrinsic motivations: Classic definitions and new directions. Contemporary Educational Psychology, 25(1), 54-67. doi: 10.1006/ceps.1999.1020

Ryan, R. M., \& Deci, E. L. (2000b). Self-determination theory and the facilitation of intrinsic motivation, social development, and well-being. American Psychologist, 55(1), 68-78. doi: 10.1037/0003-066X.55.1.68

Sheldon, K. M., \& Filak, V. (2008). Manipulating autonomy, competence, and relatedness support in a game-learning context: New evidence that all three needs matter. British Journal of Social Psychology, 47(2), 267-283.

Standage, M., Duda, J. L., \& Ntoumanis, N. (2003). A model of contextual motivation in physical education: Using constructs from self-determination and achievement goal theories to predict physical activity intentions. Journal of Educational Psychology, 95(1), 97-110. doi: 10.1037/00220663.95.1.97 
Standage, M., Duda, J. L., \& Ntoumanis, N. (2005). A test of self-determination theory in school physical education. British Journal of Educational Psychology, 75(3), 411-433. doi: 10.1348/000709904X22359

Stefanou, C. R., Perencevich, K. C., DiCintio, M., \& Turner, J. C. (2004). Supporting autonomy in the classroom: Ways teachers encourage student decision making and ownership. Educational Psychologist, 39(2), 97-110. doi: 10.1207/s15326985ep3902_2

Stoynoff, S. (1997). Factors associated with international students' academic achievement. Journal of Instructional Psychology.

Tan, K.-C. D., Goh, N.-K., Chia, L.-S., \& Treagust, D. F. (2001). Secondary students' perceptions about learning qualitative analysis in inorganic chemistry. Research in Science and Technological Education, 19(2), 223234. doi: 10.1080/02635140120087740.

Tompson, H. B., \& Tompson, G. H. (1996). International perspective: Confronting diversity issues in the classroom with strategies to improve satisfaction and retention of international students. Journal of Education for Business, 72(1), 53-57. doi: 10.1080/08832323.1996.10116826

Trigwell, K., \& Prosser, M. (1991). Improving the quality of student learning: the influence of learning context and student approaches to learning on learning outcomes. Higher Education, 22(3), 251-266. doi: 10.1007/BF00132290

Vallerand, R. J., Pelletier, L. G., Blais, M. R., Briere, N. M., Senecal, C., \& Vallieres, E. F. (1992). The Academic Motivation Scale: A measure of intrinsic, extrinsic, and amotivation in education. Educational and Psychological Measurement, 52(4), 1003-1017. doi: 10.1177/0013164492052004025

Vansteenkiste, M., Lens, W., \& Deci, E. L. (2006). Intrinsic versus extrinsic goal contents in self-determination theory: Another look at the quality of academic motivation. Educational Psychologist, 41(1), 19-31. doi: $10.1207 / \mathrm{s} 15326985 \mathrm{ep} 410144$

Wang, J. H.-Y., \& Guthrie, J. T. (2004). Modeling the effects of intrinsic motivation, extrinsic motivation, amount of reading, and past reading achievement on text comprehension between US and Chinese students. Reading Research Quarterly, 39(2), 162-186. doi: 10.1598/RRQ.39.2.2

Wehmeyer, M. L., Abery, B. H., Zhang, D., Ward, K., Willis, D., Hossain, W. A., . . . Calkins, C. (2011). Personal self-determination and moderating variables that impact efforts to promote self-determination. Exceptionality, 19(1), 19-30. doi: 10.1080/09362835.2011.537225

Wicks, R. (1996). Effects of English language proficiency on the academic performance of international students: A USQ study. Distance Education, 17(1), 196-204. doi: 10.1080/0158791960170113

Wigfield, A., \& Eccles, J. S. (1994). Children's competence beliefs, achievement values, and general self-esteem change across elementary and middle school. The Journal of Early Adolescence, 14(2), 107-138.

Wong, J. K.-K. (2004). Are the Learning Styles of Asian International Students Culturally or Contextually Based? International Education Journal, 4(4), 154-166. 
Yamazaki, Y., \& Kayes, D. C. (2004). An experiential approach to cross-cultural learning: A review and integration of competencies for successful expatriate adaptation. Academy of Management Learning \& Education, 3(4), 362-379.

Yee, L. S. (2011). Mathematics attitudes and achievement of junior college students in Singapore. Paper presented at the Annual Meeting of the Mathematics Education Research Group of Australasia, 33rd, Freemantle, Western Australia.

Yeh, C. J., \& Inose, M. (2003). International students' reported English fluency, social support satisfaction, and social connectedness as predictors of acculturative stress. Counselling Psychology Quarterly, 16(1), 15-28. doi: 10.1080/0951507031000114058

Zhao, C.-M., Kuh, G. D., \& Carini, R. M. (2005). A comparison of international student and American student engagement in effective educational practices. Journal of Higher Education, 209-231. doi: $10.1353 /$ jhe.2005.0018

Zhou, M., Ma, W. J., \& Deci, E. L. (2009). The importance of autonomy for rural Chinese children's motivation for learning. Learning and Individual Differences, 19(4), 492-498.

Zhu, Y., \& Leung, F. K. (2011). Motivation and achievement: Is there an East Asian model? International Journal of Science and Mathematics Education, 9(5), 1189-1212. doi: 10.1007/s10763-010-9255-y

KAH LOONG CHUE, is adjunct faculty and a graduate student in an EdD program. His research and teaching interests include motivation in education, learning styles, personality traits and assessment methods. Email: klchue@gmail.com

YOUYAN NIE, $\mathrm{PhD}$, is an assistant professor in the psychological studies department. Her research interests include motivation in education and human development, self-regulated learning, organizational climate in classroom and school settings and innovation in curriculum instruction and assessment. Email: youyan.nie@nie.edu.sg.

Manuscript submitted: November 1, 2014 Manuscript Revised: January 4, 2015 Accepted for publication: February 5, 2016 